\title{
La máquina esquizoide de narrar: derivas de la gauchesca en "Las actas del juicio" y Plata quemada de Ricardo Piglia
}




\title{
La máquina esquizoide de narrar: derivas de la gauchesca en "Las actas del juicio" y Plata quemada de Ricardo Piglia
}

\begin{abstract}
Resumen: no hay propiedad privada en la lengua, insisten Arlt y Brecht: la literatura deviene, entonces, superposición esquizofrénica de voces ajenas y ningún escritor puede sentirse dueño de su palabra. En Piglia, el dispositivo narrativo se concibe como relectura personal de los materiales que la tradición le facilita. En permanente intertextualidad con la gauchesca, "Las actas del juicio" y Plata Quemada metaforizan el ilícito, la subversión implícita en todo acto de escritura.
\end{abstract}

Palabras clave: Piglia, Plata Quemada, Gauchesca, esquizofrenia, "Actas del juicio".

\section{An schizophrenic storytelling machine: gauchesca's drifts in Ricardo Piglia's "Records of the trial" and Burnt money}

\begin{abstract}
According to Arlt and Brecht, there is no private property in language: literature becomes an schizophrenic overlap of foreign voices, so that no writer can feel himself owner of his own words. In Piglia, the narrative device is conceived as a personal reading of the materiales given by tradition. In a constant dialogue with gauchesca gender, "Records of the trial" and Burnt money work as a metaphor the illicit subversion implied in every act of writing.
\end{abstract}

Keywords: Piglia, Burnt money, Gauchesca, schizophrenia, "Records of the trial".

Fecha de recepción: 12 de marzo de 2017

Fecha de aceptación: 8 de mayo de 2017

Forma de citar APA: Longoni, B. (2017). La máquina esquizoide de narrar: derivas de la gauchesca en "Las actas del juicio" y Plata quemada de Ricardo Piglia. Revista Filosofía UIS, 16(2), doi: http://dx.doi.org/10.18273/revfil.v16n2-2017006

Forma de citar (Harvard): Longoni, B. (2017). La máquina esquizoide de narrar: derivas de la gauchesca en "Las actas del juicio" y Plata quemada de Ricardo Piglia. Revista Filosofía UIS, 16(2), 127-139.

Bruno Longoni: argentino. Máster en estudios avanzados en Literatura española e hispanoamericana (Universidad de Barcelona). Profesor Universidad Industrial de Santander.

Correo electrónico: brunoandreslongoni@yahoo.com.ar

* Artículo de reflexión derivado de investigación. 


\section{La máquina esquizoide de narrar: derivas de la gauchesca en "Las actas del juicio" y Plata quemada de Ricardo Piglia}

\section{1. "La propiedad es un robo"}

La literatura, explica Arlt condescendiente en una de sus Aguafuertes, es una estafa, un fraude donde el escritor "macanea a gusto", y donde el lector, por contrapartida, "recibe la mercadería y cree que es materia prima, cuando apenas se trata de una falsificación burda de otras falsificaciones" (1998, p. 57). Nuestro título está extraído, a su vez, de las notas apócrifas de Roberto Arlt que puebla las páginas de Nombre Falso, novela breve que Ricardo Piglia juzga entre lo mejor de su producción escrita. Si se lo toma con cautela, ese título expresa una idea central que el autor recupera de Brecht: "La poética pigliana ha rechazado desde sus orígenes la noción de 'propiedad' vinculada a la literatura; las ideas, como las palabras o como el dinero, están instaladas en una circulación continua, transtextual, de modo que no son de nadie pero son de todos" (Carrión, 2008, p. 15). Ello no debiera inducirnos al error de inscribir a Piglia en las huestes del posmodernismo, pues no se trata aquí de que "los libros siempre hablan de otros libros y cada historia cuenta una historia que ya se ha contado" (Eco, 1990, p. 640). La visión posmodernista de la cultura como fenómeno eminentemente intertextual que vuelve parasitario a todo sujeto discursivo ya había sido planteada previamente (Bajtin, 1990) y, huelga decir, de tan notoria resulta baladí. Las palabras son, efectivamente, deudas que nunca se saldan. Para Piglia, no obstante, todo está por escribirse, pues la literatura puede leerse -y reescribirse, por ende- de infinitas formas: cómo se escribe importa menos que cómo se lee. Lejos de crear, el escritor reorganiza las voces heredadas como la "máquina" de Macedonio en La ciudad ausente o como la voz narrativa que, en el epílogo de Plata quemada, nos informa que la novela "cuenta una historia real" surgida por completo "de fuentes directas" (Piglia, 2013, p. 167). Si la intertextualidad es una propiedad inherente a toda práctica discursiva (ningún hablante es Adán, apunta Bajtin, como para inscribir sus enunciados ex nihilo), la literatura de Piglia pretende menos disimular esas deudas intrínsecas en aras de una pretendida originalidad que ficcionalizarlas, volverlas parte central de su maquinaria narrativa 
sin dejar de subrayar su proveniencia externa. La función del autor se despoja, en consecuencia, de toda veleidad romántica vinculada a una lengua propia para asumir el caos.

Al igual que Respiración artificial, Blanco nocturno o El camino de Ida, Plata Quemada se confecciona como una suerte de convergencia de fuentes divergentes; una novela narrada "desde afuera" cuyo narrador astutamente se presenta como mero intermediario de discursos ajenos. Basta leer el íncipit para comprobarlo: "Los llaman los mellizos porque son inseparables" (Piglia, 2013, p.11). Más allá de la fragmentación ("Ilaman") de la monodia propia del policial clásico, opera a su vez un desplazamiento: el detective cede protagonismo al criminal cuyo delito, dicho sea de paso, sirve como metáfora kafkiana de la escritura; la apropiación ilegal de la palabra, bien común, se paga con el esquizofrénico asedio de las fuerzas del orden. A la isotopía estilística del policial clásico, Piglia contrapone en Plata quemada un relato policial "fruto de una investigación, el resultado de una escucha particular, la transmisión coherente de lo que 'suena' en el oído del escritor: es un robo, es un plagio de lo ya existente, es la reproducción de otras voces" (Premat, 2009, p. 209).

\section{Las actas del juicio}

Como suele ser el caso en Piglia, "Las actas del juicio" engaña en su aparente sencillez. Se trata ante todo de un texto liminar, un palimpsesto que señala el umbral que hay que franquear para ingresar a Piglia, pues allí el autor pone a dialogar los géneros fundantes de la narrativa rioplatense: último grito de la gauchesca por su entonación oral escurridiza y fugaz, sí, pero también testimonio jurídico-histórico (la non-fiction que va de Mansilla y Sarmiento a Walsh y Lamborghini) y cuento borgeano de cuchilleros con su culto al coraje, su desdoblamiento del héroe y sus laberintos cognoscitivos; materias primas, todas ellas, hábilmente reelaboradas por Piglia y por su faulkneriano y digresivo narrador cuyas "historias se enredan porque [...] no termina de entender lo que está contando" (Piglia, 2015, p. 50).

Nos referimos a Robustiano Vega, verdugo de Urquiza, quien declara ante un juzgado; la apelación al oyente responde a un arcaísmo que Piglia valora por conferirle cierta proximidad irreal al relato: "Lo que ustedes no saben es que ya estaba muerto desde antes" (Piglia, 2007, p. 66). Borges introduce ese recurso en su primer cuento de cuchilleros (luego lo abandonará y empleará hasta el hartazgo su típico narrador-testigo de segunda mano a quien le es referido un sórdido entrevero de compadritos en algún tugurio del sur). En "Hombre de la esquina rosada", el asesino asume prepotente la palabra y, más que leerlo, se diría que el lector lo oye en ronda de pulpería: "A mí, tan luego, hablarme del finado Francisco Real" (Borges, 2006, p. 218). Ambos, Rosendo Juárez y Robustiano Vega, responden altaneros a una acusación que preexiste al cuento. Lo llamativo es que 
Vega, el asesino que nos propone Piglia, no se defiende ante el tribunal ni se declara inocente, sino que presenta su asesinato como un acto ya consumado de antemano: como Pedro Páramo, Urquiza ya estaba muerto en vida y Robustiano, hombre piadoso, sólo vino a cortarle la agonía.

\section{Un hombre es muchos hombres}

Allí no terminan las coincidencias con el héroe de Rulfo: Urquiza representa también al caudillo federal, fuerza telúrica, pulsión bestial y -priapismo mediantemacho engendrador (aún hoy Entre Ríos sigue siendo provincia pródiga en Urquizas): "hasta llegar adónde llegó solo con el coraje, desde el tiempo en que empezó a arrear caballos entre los indios, cuando recién andaba cerca de los veinte y ya no se le podían contar ni los hijos, ni las leguas" (Piglia, 2007, p.72). Su configuración guarda algo del Taras Bulba de Gogol: beber y guerrear es su horizonte existencial al que se entrega casi con desgano, como si cumpliera con un destino ya escrito:

— Usted se le anima a mi mujer porque es el que manda, mi general.

— ¿ Usted cree, Chávez? —y que se viniera con él y movió un brazo así, como sin ganas, señalando la oscuridad, a ver cuál de los dos se equivocaba.

Se metieron entre los árboles. Nosotros nos quedamos en medio de toda la luz. No se escuchaba otra cosa que el viento moviendo las hojas y un olor a cuero sudado o a naranjas, y la mujer del Payo se retorcía las manos, y cuando el General salió, ya era viuda del Payo y mujer del General (Piglia, 2007, p.71).

Elipsis, principio del barroco: la muerte, nudo patógeno, queda elidida. Cubierta en primer plano, se diría que brilla por su ausencia: en "Hombre de la esquina rosada" tampoco se narra el duelo central, sino su antes y después.

\section{Salgan otros a cantar / y veremos quién es menos}

Muerto el coraje y entregado ignominiosamente a los porteños de Mitre por algún pacto secreto en la enigmática batalla de Pavón, sus acólitos se le rebelan. Si bien Urquiza es despiadado (ordena lancear a los desertores, manda al cepo al coronel Olmos cuando le cuestiona su retirada, gobierna dictatorialmente su feudo), la conspiración se produce recién cuando se atempera, como si la manada no le perdonara la decadencia al lobo desdentado y quisiera ahorrarle el escarnio de una vejez sumisa y vergonzante frente al poder central de los porteños. Este sacrificio atávico queda insinuado en el momento en que Urquiza liquida a su caballo: "Cuando se alzó pidiendo 'Un caballo que aguante, carajo', ya era otro y están los que dicen que lloraba, pero eso no, porque no era hombre para eso, para cambiar porque le falta el caballo" (Piglia, 2007, p.75). Desde que Ricardo III se muestra dispuesto a cambiar my kingdom for a horse!, lo sabemos acabado... 
El caballo es vigor: con él se va el reinado. Desde el Fierro de Hernández hasta Hombres de a caballo de Viñas o Nadie nada nunca de Saer, el caballo ha sido un sema fuerte en la literatura local: signo rural y viril, orgullo criollo y nacionalismo argentino.

El círculo se cierra con Robustiano Vega: "Pedí seis hombres y antes que clareara me apuré a hacerlo, como quien le revienta la cabeza a un potro quebrado" (Piglia, 2007, p.78). Y así como la identidad del hermano del moreno se funde con la de Fierro en "El fin", Vega se vuelve el otro: "no tenía destino sobre la tierra y había matado a un hombre" (Borges, 2006, p. 376). Urquiza, en cambio, se asemeja al minotauro de "La casa de Asterión" que, para sorpresa de Teseo, evita defenderse: "Nos recibió igual que si nos esperara y no se defendió" (Piglia, 2007, p. 79). Así nos tenga deparada la muerte, el destino le confiere un sentido a la existencia: para qué, entonces, andar interfiriendo con sus designios.

\section{Siglo $X X$, cambalache}

Frente a la unidad del policial clásico, en Plata quemada todo es doble: dos ciudades, Buenos Aires y Montevideo; dos episodios centrales, el asalto a un camión de caudales en septiembre de 1965, por un lado, y la resistencia febril de los delincuentes sitiados por dos fuerzas policiales (la uruguaya y la argentina) por más de quince horas en una vorágine de drogas y violencia; dos relatos, el policial y la pesquisa que Piglia (personaje) conduce; dos protagonistas, por último, el Nene Brignone y el Gaucho Dorda, fundidos en uno, más allá de la relación homoerótica que los úne.

Porque el Gaucho y el Nene eran, para el Gaucho, uno solo. [...] 'Un caso muy interesante de simbiosis gestáltica. Son dos pero actúan como una unidad. El cuerpo es el Gaucho, el ejecutor pleno, un asesino psicótico; el Nene es el cerebro y piensa por él' (Piglia, 2013, p.49).

De allí a que la mítica (y apócrifa) banda que musicaliza los encuentros del Nene y Giselle, Head and Body, y sus canciones (Parallel lives y Brave Captain) sirvan como ecos del dúo protagónico y del brutal policía que los acecha, el capitán Silva. El Nene y el Gaucho se inscriben en una larga tradición delincuencial que en la literatura argentina se retrotrae hasta "El matadero", el cuento de Echeverría donde, al igual que en Plata quemada, la ilegalidad es estructural y constituye menos una excepción que la norma. Leemos en la novela de Piglia, por ejemplo, que el tesorero que carga el portafolios a menudo fantasea con reemplazarlo por plata falsa (24), que Dorda es violado por los enfermeros del pabellón psiquiátrico adonde es enviado (52), que la "merca" de primerísima que consume una noche el Gaucho proviene de "la guantera del checo de un diputado" (55), que la banda cae por un "buchón" que Silva, torturador de sus detenidos, tenía enganchado "a cambio de dejarlo circular por el Bajo con drogas y mujeres" (59) y por un miembro 
del concejo deliberante "que en otro lugar habría sido un hombre de la mafia" (62), que la banda consigue cruzar al Uruguay gracias a "los tipos de la aduana y a la gente de la prefectura que hacían la vista gorda en los cruces clandestinos a la otra orilla" (63), que, en un claro guiño a Los siete locos, sus armas provienen de un suboficial del Ejército (64), que "todos los argentinos que andaban por Montevideo eran contrabandistas" (71) y que la policía argentina no respondía a un ideal de justicia sino que "lo más probable es que haya querido matarlos y no agarrarlos vivos para impedir que incriminaran a los oficiales que (según la misma fuente) habrían participado secretamente en el operativo sin recibir la parte del botín que había sido pactada" (97). Siguiendo el esquema social del policial negro de Chandler y Hammett, aquí todas las relaciones humanas son interesadas y todas, sin excepción, están atravesadas por el dinero (idea arltiana, para quien el matrimonio es una forma de prostitución encubierta): tras varios encuentros ocasionales entre el Nene y Giselle en un departamento vacío, "él empezó a dejarle plata, que ella aceptaba con naturalidad" (81). La impresión de ilegalidad generalizada queda establecida, finalmente, cuando comparamos la escena del atraco con el final de la novela; ambos vehículos, auto y ambulancia, se alejan conduciendo a contramano del tráfico. Ni siquiera el narrador que construye Piglia está a salvo; a juzgar por sus lunfardismos ("buchón" por delator, "merca" por cocaína, la "tartamuda" por la ametralladora, "garchar" por tener sexo, "cana" o "yuta" por policía, "chorro" por ladrón, "checo", en inversión de coche) y por una sintaxis que, idiosincrática de la oralidad rioplatense, desplaza el sujeto oracional a posición final ["Tenía varias obsesiones, Malito" (16); "Era un bulto enorme, el gordo Spector" (29) ; "Qué manubrio esa nena con el vascolet", (35); "Porque se parecía a su madre, la nena" (101); "y andaba por el patio sin llorar, el Gaucho" (150)], su procedencia patibularia lo muestra cómplice de un universo ideológico viciado o corrompido.

Curiosamente, la relación del Cuervo Mereles y Blanca Galeano, quien "se calentó como loca" (21) cuando supo a qué se dedicaba su novio pistolero, o la del Gaucho y el Nene, subversiva a todas luces para una época que no vacila a lo largo de la novela en asociar homosexualidad a criminalidad, es decir, aquellas relaciones que los discursos médicos, los legajos policiales y la crónica policial no dudan en categorizar como "enfermizas" o "patológicas", son las únicas, a su vez, que no aparecen indisolublemente atravesadas por lo económico, como si funcionaran como prolepsis de la rebelión final: la quema del dinero, gesto ético y estético (los billetes son comparados con mariposas ardientes o pájaros de fuego) que deja como único residuo "una columna bellísima de cenizas azules [...] una pila funeraria con los valores de la sociedad" (Piglia, 2013, p. 132). 


\section{Luche y vuelve}

Ni el Nene Brignone ni el Gaucho Rubio han sido pobres; no hay, en Piglia, determinismo, sino una difusa mezcla de autodeterminación y coacción social. "Hijo primogénito de un acaudalado empresario de la construcción, residente en el barrio de Belgrano" (Piglia, 2013, p. 65), el Nene ingresa en el hampa por error para confesar que "en la cárcel me hice puto, drogadicto, me hice chorro, peronista, timbero" (65). En ese caos de epítetos peyorativos que el Nene despliega, como el Gaucho con sus vejaciones sufridas, casi con orgullo, se presiente la tensión social ("peronista") en un contexto de dictaduras militares que proscribieron a la fuerza política mayoritaria del país, cuya filiación, por otro lado, implicaba de por sí una caída en la ilegalidad: surgen en estos años los montoneros y la lucha armada clandestina. Ello explica en parte la etiqueta de "ideológicos" que el capitán Silva imprime sobre los crímenes pos revolución libertadora, o "la resaca que dejó el peronismo" (47). Ya sitiados por trescientos policías (número significativo desde la batalla de las Termópilas), los delincuentes sueñan (deliran) con un regreso glorioso de Malito que asume la forma de la gran fantasía nacional alentada en secreto durante los años de exilio de Perón: "Iba a venir a sacarlos, iba a venir con refuerzos, Malito [...] loco pero muy inteligente, siempre a distancia, sin dar mayor bola, pero muy derecho con la gente suya, un tipo que no los iba a dejar en la estacada" (140).

La conversión al crimen responde, al menos en el caso del Nene Brignone, a un "verdugueo" sistemático que la institución administra sobre el sujeto para vaciarlo ideológica y sexualmente, a un disciplinamiento, en fin, de corte foucaultiano: "La prisión no puede dejar de fabricar delincuentes. Los fabrica por el tipo de existencia que hace llevar a los detenidos [...] y al imponerles coacciones violentas; [...] todo su funcionamiento se desarrolla sobre el modo de abuso de poder" (Foucault, 2014, p. 246). En vez de reformar a los sujetos para su reinserción en la sociedad, la cárcel los corrompe, los pervierte, los envenena, en palabras del Nene: "Por eso el que va preso es carne de cárcel, sale y vuelve, sale y vuelve, y eso pasa por el gran veneno que te inculcan ahí adentro" (Piglia, 2013, p. 68).

Esquizofrénico y afásico hasta bordear la mudez, femenino en su risa de nena y viril en su ferocidad asesina, el Gaucho Rubio (vistoso oxímoron que condensa la dicotomía sarmientina), por su parte, proviene del campo y se inscribe tanto en la línea de Santos Vega, Moreira y Fierro ["un matrero, un retobao, un asesino, hombre de agallas y de temer en la provincia de Santa Fé, en los almacenes de la frontera, al Gaucho siempre le habían gustado los hombres" (152)], como en la de Raskolnikov, Erdosain y Astier ["Lo Ilevaban bajo los puentes y lo sodomizaban [...] y lo disolvían en una niebla de humillación y de placer, de la que salía a la vez avergonzado y libre" (152); carga con su colchón meado como quien carga, 
desde niño, con su cruz: el estigma de su madre que le vuelve como un rezo en las voces de su mente afiebrada: "Vos vas a terminar mal" (149). Si bien Dorda es, como el Nene, "carne de frenopático", su perfil es menos foucaultiano que deleuzeano; entendiendo que "la esquizofrenia es el producto de la máquina capitalista" (Deleuze \& Guattari, 2004, p. 40), el Gaucho Rubio es el hombre desterritorializado por excelencia: su amnesia y sus carencias lingüísticas responden a una subjetividad moderna signada por la fluidez esquizofrénica y la disipación despersonalizante que opera en la máquina capitalista (idea recurrente, la "máquina", en Piglia, como la expresión "darles máquina" y "darles goma" -borrarlos- que la policía suele emplear en la novela). Por otro lado, como señala Selnes (2006), hay un marcado paralelismo entre la cacofonía coral que fluye en las voces narrativas y aquellas que resuenan dentro de la cabeza del esquizofrénico Dorda, "a parallel which reflects the pressure of surveillance and punishment on the human psyche as well as the vertiginous circulations of the capitalist machine" (2006, p.8). Desde nuestro punto de vista ello responde a que, de haber algún enigma por develar en Plata quemada, probablemente se trate de la metáfora escritural que todos los personajes de la novela encarnan: desde el joven cronista de El Mundo, Emilio Renzi, alter ego autoral que encarna al escritor-oyente que interroga e interpreta la realidad en clave de tragedia griega (hubris, muthos, pathos), al radiotelegrafista de la policía uruguaya, Roque Pérez (iniciales, apunta Premat, que coinciden con las del autor), cuyo trabajo consiste en reconstruir y resemantizar el caos de voces que proviene del departamento cercado ["Se producían ciertas interferencias y estaba entonces conectado con el espíritu de toda la ciudad" (140)], pasando por el Nene Brignone quien, en su reclusión carcelaria, pasa días enteros fabulando ficciones ["Vivís en la cabeza, te metés ahí, te hacés otra vida"(67)] hasta el esquizofrénico/afásico Dorda quien, como el narrador de El silenciero de Di Benedetto, se siente tan carente de voz propia como asfixiado por la invasión desenfrenada de discursos superpuestos.

\section{Escritura esquizoide}

Escritura esquizoide, entonces, la de Piglia; máquina escritural que se reapropia inescrupulosamente de la tradición rioplantense y la resemantiza: del Fausto de Estanislao del Campo ("Una vez lo echaron del cine parroquial porque se sacó la chota y empezó a mear: en la película vio a un chico que estaba orinando, de espaldas, en medio del campo", Piglia, 2013, p.57) a "La gallina degollada" de Quiroga ["De chico la finada madre lo sorprendió cuando cortaba en dos a un pollito vivo con una tijera de esquilar y se lo llevó al comisario, para que lo ponga preso" (51)]; de El beso de la mujer araña de Puig ["En Arenas de Iwo Jima -empezó de golpe a delirar el Cuervo- los tipos se tiran en un pozo y aguantan la embestida de los tanques..." (136)] a Los siete locos de Arlt ["Sentía de pronto la necesidad de humillarse"(73)]; de "Funes, el memorioso" de Borges ["Si yo te contara las cosas que pensé estando en cafúa habría para hablar, no sé, la misma 
cantidad de tiempo que estuve preso" (67)] a Una Excursión a los indios ranqueles de Mansilla ["me dicen que ahí murió un cacique, un indio puto, ranquel, murió ahogado" (49)]; de La cautiva de Echeverría ("La subieron a un carro y la bajaron en un prostíbulo en Chivilcoy (...) y el Gaucho entendió esas palabras, las palabras que decía la polaca, la cautiva, como si fueran contraseñas" (161) a Operación masacre de Walsh ("¿Una crónica? ¿Veraz? No creo que tengas las bolas" (135); de "El Fiord" de Lamborghini (“'La vuelta, las pelotas', pensaba el Nene, 'lo único que tenemos en común es que nos picanean para averiguar si somos muñecos de la CGT'" (43) hasta (acaso el más evidente de todos) el Martín Fierro de Hernández (y Cachafaz de Copi, su reescritura en clave queer).

\section{8. ¿Derivas de las gauchesca?}

A esta altura de nuestra investigación, cabría interrogar la pertinencia de lo sugerido en el título de nuestro trabajo, pues el binomio Dorda-Brignone reelabora, hasta en la muerte recargada de simbología cristiana, al de Fierro-Cruz: "El Nene le sonrió y el Gaucho Rubio lo mantuvo en sus brazos como quien sostiene a un Cristo. El Nene se metió con dificultad la mano en el bolsillo de la camisa y le alcanzó la medallita de la Virgen de Luján" (Piglia, 2013, p. 148). Son muchos y variados los rasgos formales de la gauchesca (particularmente, del Fierro) a los que Piglia apela en esta y en otras novelas suyas: el uso de un registro oral; la sutil aprensión del habla rural y popular; el protagonismo cedido a personajes marginales cuyos crímenes expresan un aspecto esencial (y reprimido) de la sociedad (outlaw es el anglicismo que Sarmiento emplea en su Facundo para referirse a los gauchos matreros) desde un narrador empático que, en Hernández mas no en Ascasubi o en Estanislao del Campo, congenia con su héroe y narra desde un espacio amenazado por el poder central. Si en el Fierro la estructura estatal se presenta, en una suerte de visión foucaultiana avant la lettre, como máquina generadora de exclusión, injusticia y salvajismo (recordemos que en el poema hernandiano es el reclutamiento arbitrario, el maltrato y la vejación en la frontera lo que arroja al héroe al asesinato del moreno en un baile), otro tanto podría decirse, como ya hemos apuntado, sobre Plata quemada.

Por otro lado el Fierro, el gran poema nacional sobre la redención cristiana de un gaucho asesino, se resemantiza en la petición final del Gaucho Dorda; tras haber pasado la noche entera volado en drogas y acribillando policías entre risas, su funambulesca redención opera menos como la alegoría moralizante que Hernández confeccionó en la segunda parte de su poema que como su inversión siniestra: "Tráiganme un cura -dijo-. Me voy a confesar" (Piglia, 2013, p.155). Ya no hay salvación para este gaucho matrero; ni siquiera la victoria pírrica que Hernández reserva a su héroe cristianizado. Dorda ha nacido en una época equivocada, observa Brignone; una época, como la de Fierro, signada por la proscripción y la persecución ideológica (del federalismo en 1872; del peronismo 
en 1967) pero que, a diferencia de la Argentina de Sarmiento, cuenta con una estructura estatal mucho más aceitada en sus funciones de control y represión policial. Se prepara así el terreno para un Via Cruxis que ni siquiera Fierro debió tolerar: "Un Cristo, anotó el chico de El Mundo, el chivo expiatorio, el idiota que sufre el dolor de todos. [...] El pistolero herido era un baño de sangre viva y palpitante todavía, que parecía sonreír y murmurar" (163).

Por último, hay un punto en el cual el poema de Hernández y el policial negro coinciden: la idea del crimen como espacio donde se juega la verdadera naturaleza de nuestra sociedad, donde las contradicciones ideológicas se expresan con extrema nitidez.

\section{Instrucciones para quemar la plata}

Ninguna de todas las líneas temáticas que hemos desarrollado a lo largo de este trabajo se retoma, lamentablemente, en la versión cinematográfica dirigida por Marcelo Piñeyro; versión preocupada, más bien, en "transformar una historia de fuerte conflictividad social en una relación casi adolescente de una pareja gay" (Berg, 2001, p. 97). El Gaucho Dorda es inexplicablemente españolizado (sacrificando, en consecuencia, el valioso intertexto con la gauchesca), el Cuervo Mereles opera como la voz de la homofobia, las fuerzas policiales son representadas en su tradicional rol de restauradoras del orden y la película en su conjunto decide centrarse en el triángulo amoroso viciado por vestigios de pudor y culpa por completo ajenos a los personajes de la novela, y en detrimento de la potencia simbólica que la quema del dinero acarrea, sobre todo en el contexto global de los gobiernos neoliberales que, en la década de los '90, instalaron con fuerza el culto al lucro y a la especulación financiera como fines en sí mismos, y donde la célebre pregunta brechtiana que sirve de epígrafe a la novela ("¿Qué es robar un banco comparado con fundarlo?") habría disparado una discusión ideológica infinitamente más enriquecedora que la descafeinada crítica liberal que censura, no sin fuertes dosis de corrección política, el prejuicio hacia las minorías sexuales.

\section{Retrato de un hombre de letras}

Recientemente fallecido desde la referencia temporal que la enunciación de este trabajo implica, la ausencia física de Piglia deja un enorme vacío en las letras argentinas. La máquina escritural que Piglia pone en marcha opera como una de las formas que la vanguardia latinoamericana actual asume en franca oposición con los prejuicios románticos sobre la originalidad del autor y la exclusividad de su obra. Uno de sus escritores argentinos contemporáneos más admirados, Juan José Saer, suponía una representación de la escritura como estricta delimitación negativa de un territorio narrativo propio en posición de repliegue frente a la 
industria cultural y los medios masivos. En más de un sentido, Piglia supone su exacta inversión: un escritor que ficcionaliza la desterritorialización planteada por Deleuze (2004), que traduce la superposición de voces, la liquidación posmodernista de todo metarrelato y de toda jerarquía en el arte y el caos de la existencia en el capitalismo tardío en una forma literaria, en una máquina narrativa esquizoide que no vacila en reescribir lo ya escrito, así como el Gaucho Dorda, el Nene Brignone y el Cuervo Mereles echan mano a una plata que, como las palabras, entes en perpetua circulación, no son de nadie (o son de todos) $\varphi$

\section{Referencias}

Arlt, R. (1998). Aguafuertes. Buenos Aires: Losada.

Berg, E. (2001). Asesinos por naturaleza: sobre Plata quemada de Ricardo Piglia (segunda reflexión). CELEHIS: Revista del Centro de Letras Hispanoamericanas, (13) 95-109.

Borges, J. L. (2006). Obras completas. Buenos Aires: Emecé.

Carrión, J. (2008). Dos por cuatro: la multiplicación pigliana. El lugar de Piglia: crítica sin ficción. Madrid: Candaya.

Cerezo, I, M. (2006). Poética del relato policíaco: de Edgar Allan Poe a Raymond Chandler. Murcia: Editum.

Deleuze, G \& Guattarri, F. (2004). El Anti-Edipo: capitalismo y esquizofrenia. Madrid: Paidós.

Eco, U. (1990). Apostillas a El nombre de la rosa. Barcelona: Lumen.

Foucault, M. (2014). Vigilar y castigar: Nacimiento de la prisión. Buenos Aires: Siglo XXI.

Garabano, S. (2003). Homenaje a Roberto Arlt: Crimen, falsificación y violencia en Plata Quemada. Hispamérica, 32(96), 85-90.

Link, D. (2003). El juego de los cautos. Literatura policial: de Edgar A. Poe a P.D. James. Buenos Aires: La Marca.

Oviedo, J. M. (2001). Historia de la literatura hispanoamericana, Vol. IV. Madrid: Alianza.

Piglia, R. (1986). Tesis sobre el cuento en "Formas Breves". Madrid: Anagrama. 
Piglia, R. (2007). Las actas del juicio en La invasión. Barcelona: Anagrama.

Piglia, R. (2013). Plata Quemada. Barcelona: Random House Mondadori.

Piglia, R. (2014). Nombre falso. Buenos Aires: Debolsillo.

Piglia, R. (2015). Por un relato futuro: conversaciones con Juan José Saer. Barcelona: Anagrama.

Premat, J. (2002). Los espejismos del decir. Oralidad y experiencia en Plata Quemada de Ricardo Piglia. Pandora: revue d'etudes hispaniques, (2), 169-180.

Premat, J. (2009). Piglia: Loco lector, en Héroes sin atributos: Figuras de autor en la literatura argentina. Buenos Aires: F.C.E.

Rest, J. (1974). Diagnóstico de la novela policial. Crisis, (15), 30-39.

Selnes, G. (2006). Parallel Lives: Heterotopia and Delinquency in Piglia's Plata quemada. Ciberletras: Revista de crítica literaria y de cultura, (15), 10. 